Dept. of Food Hygiene,

Faculty of Vet. Med., Suez Canal University, 41522- Ismailia, Egypt.

\title{
OCCURRANCE OF ENTEROBACTER SAKAZAKII IN EGYPTIAN INFANT FORMULA MILK
}

(With One Table and 2 Figures)

\author{
By \\ O.H.R. EL-KOSI and M.M. OSMAN* \\ *Dept. of Dairy, Faculty of Agriculture, Suez Canal University, \\ 41522- Ismailia, Egypt. \\ (Received at 28/2/2009) \\ تواجد ميكروب الإتتيروباكتر ساكازاكى فى ألبان الأطفال المصرية \\ عمر حسن رفعت القوصى ، مجلى محمد عثمان
}

يعتبر ميكروب الإنتيروباكتر ساكاز اكى "Enterobacter sakazakii" أحد أسباب وفاة

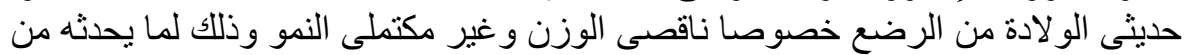

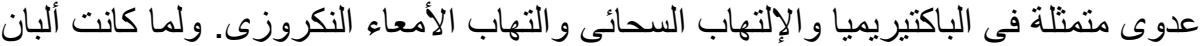

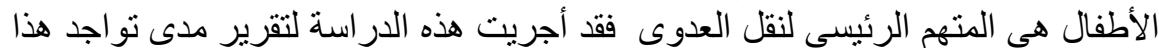

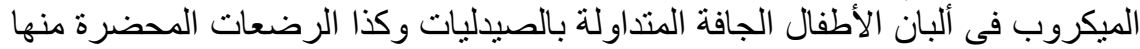

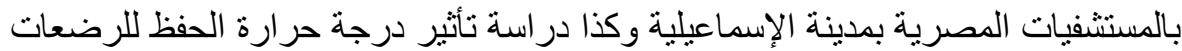

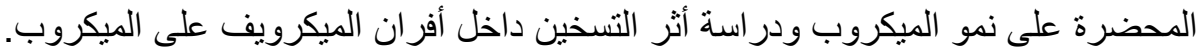

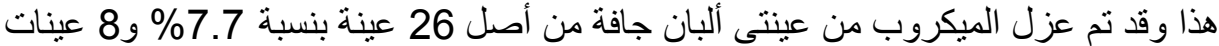

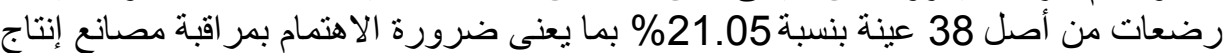

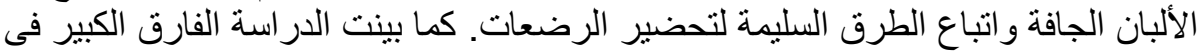

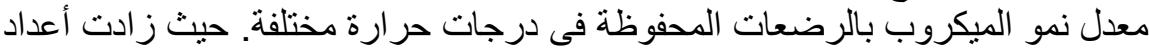

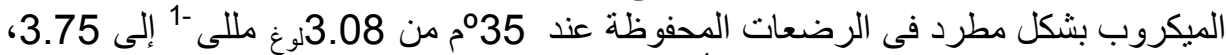

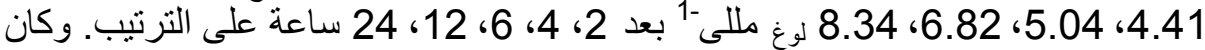

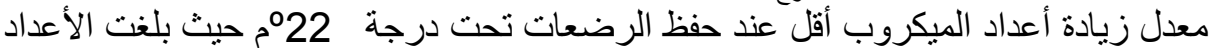

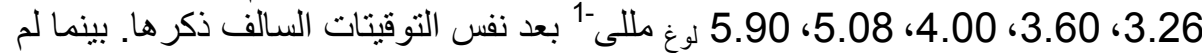

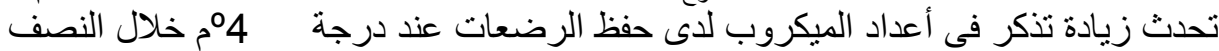

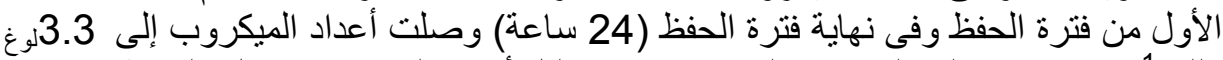

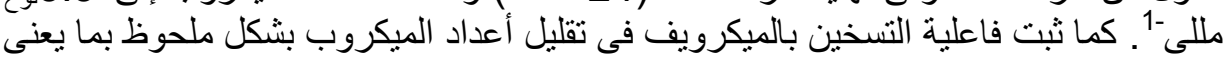

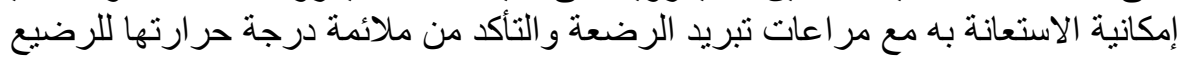
قبيل تقديمها له.

\section{SUMMARY}

Enterobacter sakazakii has been implicated to be a rare, but lifethreatening cause of outbreaks and sporadic cases of neonatal infections, 
particularly in premature underweight babies. The prevalence of E. sakazakii in powdered and hydrated infant formula milk (IFM) collected from Egyptian pharmacies and hospitals in Ismailia City was investigated using FDA enrichment procedure. A total of 64 samples (26 powdered +38 hydrated) were tested. The organism was isolated from 2 powdered $(7.7 \%)$ and 8 hydrated $(21.05 \%)$ samples. The organism grew rapidly at $35^{\circ} \mathrm{C}$ in which its population increased from $3.08 \log \mathrm{cfu} \mathrm{ml}^{-1}$ at 0 time to $3.75,4.41,5.04,6.82$, and $8.34 \log \mathrm{cfu} \mathrm{ml}^{-1}$ after 2, 4, 6, 12, and 24 hours, respectively. At $22^{\circ} \mathrm{C}$, E. sakazakii increased from 3.08 $\log \mathrm{cfu} \mathrm{ml}^{-1}$ at 0 time to $3.26,3.60,4.00,5.08$, and $5.90 \log \mathrm{cfu} \mathrm{ml}^{-1}$ after $2,4,6,12$, and 24 hours, respectively. It showed no growth at $4^{\circ} \mathrm{C}$ through the first 12 hours and very slow growth along the whole period reaching only $3.3 \mathrm{log} \mathrm{cfu} \mathrm{ml}^{-1}$ by the end of the 24 hour keeping period. Upon investigating the killing effect of microwave heating, it was proved to be a convenient and fast method to reduce E. sakazakii counts in mild, moderate and massively contaminated IFM samples. However, care should be taken to ensure that milk is adequately cooled to the required temperature before being fed to an infant.

Keywords: "Enterobacter sakazakii, powdered/hydrated infant formula milk, storage temperature, microwave heating"

\section{INTRODUCTION}

Enterobacter sakazakii is a motile, non-spore forming, facultative anaerobe, Gram negative rod. It was previously referred to as "yellow-pigmented Enterobacter cloacae" until it was designated a unique species by Farmer et al. (1980). E. sakazakii is an emerging pathogen associated with life-threatening neonatal infections. It was first associated with cases of neonatal meningitis in 1958 (Urmenyi and Franklin, 1961). The organism causes bacteraemia, necrotizing enterocolitis and infant meningitis in premature babies and neonates. Reported case-mortality meningitis rates vary from 40 to $80 \%$ among infected infants, with the majority of those who survive Enterobacterassociated meningitis (94\%) developing an irreversible neurological sequela (Willis and Robinson, 1988). The reservoir for E. sakazakii is unknown, however, a growing number of reports suggest a role for powdered milk-based infant formulas as a vehicle for infection (Biering et al., 1989; Simmons et al., 1989; Van Acker et al., 2001; Iversen, and Forsythe, 2003; Gurtler et al., 2005; Shaker et al., 2007). Indeed, E. sakazakii has been isolated from environmental sources and from food other than infant formula and milk powder (Kandhai, et al., 2004; 
Friedemann, 2007), but why it is associated only with the consumption of infant formulae is still unclear (Conte and Passantino, 2008). Recent taxonomic analyses have determined that E. sakazakii comprises a number of genomospecies, and it has been proposed that E. sakazakii may be reclassified as a novel genus, "Cronobacter". Cawthorn, et al. (2008) recommended the use of accurate methods for rapid detection and identification of this group of micro-organisms, since even low cell numbers have been reported to cause disease. In a recent review described the ubiquitous nature of the organism in food other than infant formula, E. sakazakii could be isolated from plant food and food ingredients like cereal, fruit and vegetables, legume products, herbs and spices as well as from animal food sources like milk, meat and fish and products made from these foods. The spectrum of E. sakazakiicontaminated food covers both raw and processed food. The kind of processing of $E$. sakazakii-contaminated food was not restricted to dry products. Fresh, frozen, ready-to-eat, fermented and cooked food products as well as beverages and water suitable for the preparation of food, were found to be contaminated by E. sakazakii (Friedemann, 2007). Concerning its tolerance toward environmental stresses, Lin and Beuchat (2007) demonstrated that E. sakazakii can survive for up to 12 months in infant cereals having a wide range of $a_{w}$ when storage is at temperatures simulating those to which they may be exposed during distribution, at retail, and in the home. Also, Arku et al. (2008) investigated the survivability of four strains of E. sakazakii upon spraydrying and found that all tested strains had the ability to survive the spray drying process and were detected in the powders with low inoculums $\left(10^{2} \mathrm{cfu} / \mathrm{g}\right.$ dry wt $)$ and enumerated in all the powders with the high inoculums $\left(10^{7} \mathrm{cfu} / \mathrm{g}\right.$ dry wt) for at least 12 weeks. They concluded that the controls in place to prevent E. sakazakii from getting to the spray drier are essential. Iversen and Forsythe (2004) concluded that hygienic production of powdered IFM and milk production as monitored by control of Salmonella and enumeration of Enterobacteriaceae did not control E. sakazakii. Indeed, it has been stated that, the effectiveness of prevention depends on the degree of contamination and contamination sites, which are generally unknown (Kandhai, et al., 2004). The present study has three aims; reporting to what extent Egyptian powdered and hydrated infant milk formulae are contaminated with E. sakazakii, monitoring the behavior of an isolated E. sakazakii organism in hydrated infant milk formula in different incubation temperatures, and investigating the killing effect of microwave heating on the organism. 


\section{MATERIALS and METHODS}

\section{First: Occurrence of $\boldsymbol{E}$. sakazakii in infant formula milk}

A total of 64 infant formula milk (IFM) samples (26 powdered + 38 hydrated) were collected from different Egyptian pharmacies and hospitals in Ismailia City. Collected samples were investigated using the current Food and Drug Administration (FDA, 2002) method which includes a pre-enrichment procedure in buffered peptone water (BPW), enrichment in Enterobacteriaceae enrichment (EE) broth, plating on violet red bile glucose agar (VRBG) and picking of five grown colonies onto trypticase soy agar (TSA) plates, which are incubated at $25^{\circ} \mathrm{C}$ for 48-72 hours. Yellow-pigmented colonies, typical for E. sakazakii, on the TSA plates are confirmed using the API 20E biochemical strips.

Second: Effect of incubation temperature on $E$. sakazakii growth

Hydrated IFM was prepared according to the manufacturer direction inoculated with one of the isolated E. sakazakii before being aseptically subdivided into $3 \times 5$ bottles. The first set of bottles $(\mathrm{No}=5)$ were kept at $4 \pm 1^{\circ} \mathrm{C}$, the second set were held at $22 \pm 1^{\circ} \mathrm{C}$, while the third set of bottles were held at $35 \pm 1^{\circ} \mathrm{C}$. Enterobacter sakazakii count of the hydrated IFM was done according to FDA (2002) following preparation (0 time). A separate bottle from each set was examined after 2, 4, 6, 12 and 24 hours of incubation at the specified temperatures for E. sakazakii count.

\section{Third: Killing effect of microwave heating on $E$. sakazakii}

Hydrated IFM was inoculated with E. sakazakii with 3 different microbial population densities (simulating mild, moderate and massive contaminated formulae). Each preparation of the 3 inoculated IFM was further subdivided aseptically into $4 \times 100 \mathrm{ml}$ bottled portions. Each bottle was examined for E. sakazakii count before and after heating in a household microwave oven (KOG-134K, 1000 Watt, 2450 megahertz) for 20, 40, 60 and 80 seconds. The temperature following each heating process was monitored in a pilot bottle containing the same quantity of IFM.

\section{RESULTS}

Table 1: Occurrence of E. sakazakii in powdered and hydrated IFM

\begin{tabular}{|c|c|c|c|c|c|}
\hline \multicolumn{3}{|c|}{ Powdered samples } & \multicolumn{3}{c|}{ Hydrated samples } \\
\hline No & +ve & $\%$ & No & +ve & $\%$ \\
\hline 26 & 2 & 7.69 & 38 & 8 & 21.05 \\
\hline
\end{tabular}

No: Number of examined IFM samples

+ve: Number of positive samples (containing E. sakazakii) 


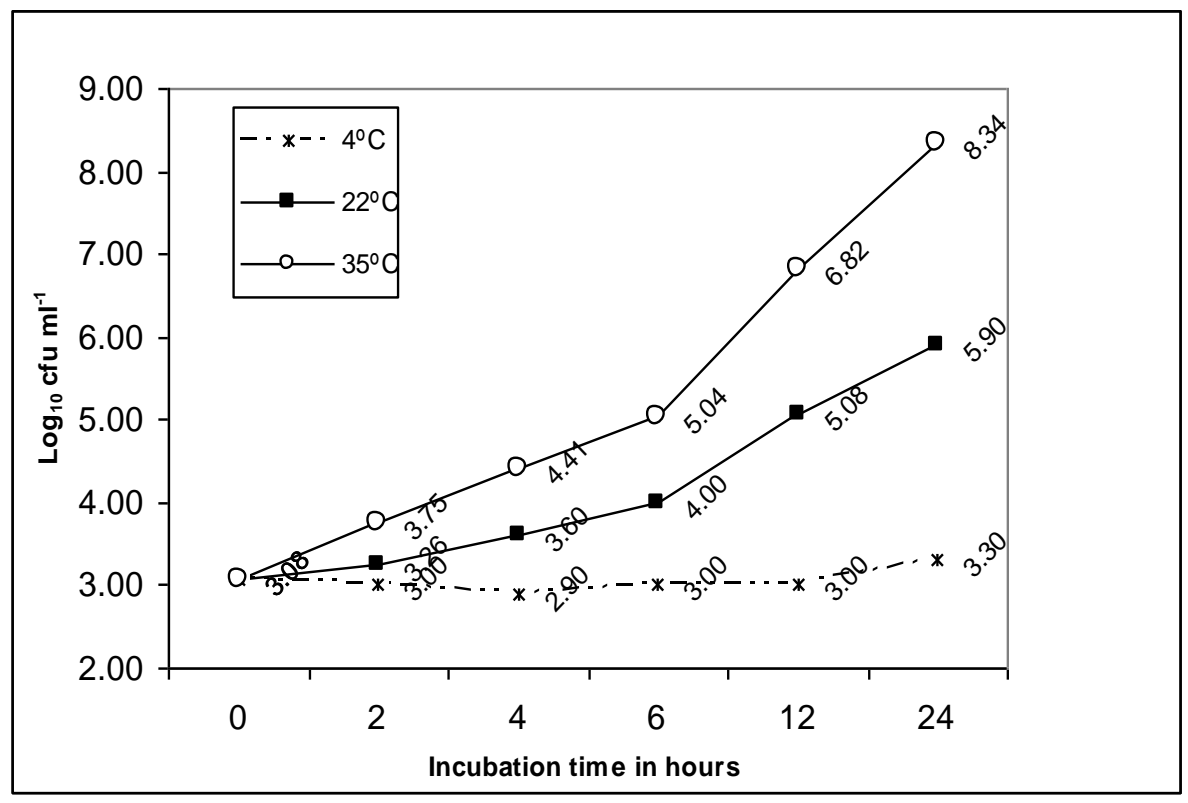

Fig. 1: Effect of storage temperature on the growth of E. sakazakii

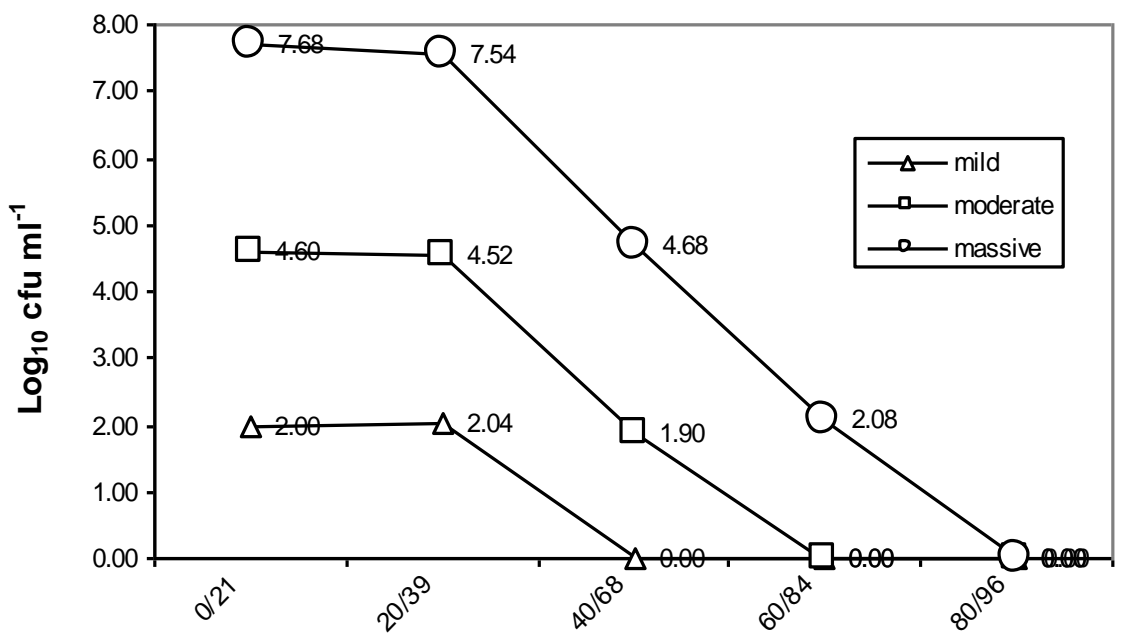

Heating time (seconds)/achieved temperature $\left({ }^{\circ} \mathrm{C}\right)$

Fig. 2: Killing effect of microwave heating on E. sakazakii 


\section{DISCUSSION}

\section{First: Occurrence of $\boldsymbol{E}$. sakazakii in infant formula milk}

The present study gives an idea about the prevalence of E. sakazakii in powdered and hydrated infant formula milk collected from Egyptian pharmacies and hospitals in Ismailia City. As outlined in the presented Table 1, only two out of the 26 powdered IFM samples representing $7.69 \%$ were contaminated by E. sakazakii. Hydrated samples showed more incidence in which $21.05 \%$ (8/38 samples) were positive. Such higher incidence in hydrated samples reflects the contribution of other environmental cross contaminating sources during IFM preparation. Temperature abuse of hydrated samples may also constitute another cause for the higher positive percentage. These results appear to be not far from those reported by Nazarowec-White and Farber (1997) and Shaker et al. (2007). Food and Agriculture Organization (FAO) categorized Enterobacter sakazakii among microorganisms of great concern with powdered infant formula due to the clear evidence of a causal association between their presence in powdered infant formula and illness in infants. Also, according to Regulation (EC) No. 2073/2005 on the microbiological criteria for foodstuffs, E. sakazakii is considered a microorganism of greatest concern in infant formulae and follow-on formulae. It is included within "safety criteria". However, Friedemann (2007) mentioned that, Although E. sakazakii-contaminated food do not have general public health significance, measures for prevention should consider its presence in food, food ingredients, their processing and preparation as possible source of contamination, colonization or infection. Hence, such obtained results should alert concerned authorities to be more careful in supervising IFM producing factories as well as assuring the right way of preparing and keeping hydrated IFM by concerned hospital stuffs.

\section{Second: Effect of incubation temperature on $E$. sakazakii growth}

Since delayed consumption of reconstituted infant milk formulae in conjunction with temperature abuse are considered to be fairly common, the growth pattern of E. sakazakii was followed up at some specified temperatures. The used temperatures were $4^{\circ} \mathrm{C}$ (representing refrigerated storage), $22^{\circ} \mathrm{C}$ (representing room temperature), and $35^{\circ} \mathrm{C}$ (representing bottle warmer temperature). The results presented in Fig. 1 showed rapid microbial growth at $35^{\circ} \mathrm{C}$ in which the organism population increased from $3.08 \mathrm{log} \mathrm{cfu} \mathrm{ml}^{-1}$ at 0 time to $3.75,4.41,5.04$, 6.82, $8.34 \log \mathrm{cfu} \mathrm{ml}^{-1}$ after 2, 4, 6, 12 and 24 hours, respectively. At $22^{\circ} \mathrm{C}$, E. sakazakii grew moderately and increased from $3.08 \log \mathrm{cfu} \mathrm{ml}^{-1}$ 
at 0 time to $3.26,3.60,4.00,5.08$, and $5.90 \log \mathrm{cfu} \mathrm{ml}^{-1}$ after 2, 4, 6, 12 and 24 hours, respectively. On the other hand, the organism showed no growth at $4^{\circ} \mathrm{C}$ through the first half of the keeping period and very slow growth along the second half as it reached only $3.3 \mathrm{log} \mathrm{cfu} \mathrm{ml}{ }^{-1}$ by its end. Likely results have been recorded by Richards et al. (2005) and Gurtler and Beuchat (2007). These results indicate that hydrated IFM should be consumed immediately after preparation or held at $4^{\circ} \mathrm{C}$ for no longer than 12 hours.

\section{Third: Killing effect of microwave heating on $E$. sakazakii}

The killing activity of microwaves of $2450 \mathrm{MHz}$ frequency and 1000 Watt power on E. sakazakii inoculated at 3 different microbial population densities (simulating mild, moderate and massive contaminated formulae) was investigated Fig 2. The organism population in mild-contaminated samples $\left(2.0 \mathrm{log} \mathrm{cfu} \mathrm{ml}^{-1}\right)$ couldn't be isolated after exposing to microwave heating for $\geq 40$ seconds. Moderately-contaminated samples (4.6 log $\mathrm{cfu} \mathrm{ml}^{-1}$ ) showed somewhat similar pattern of microbial count reduction. The organism population decreased to 4.52 and $1.9 \log \mathrm{cfu} \mathrm{ml}^{-1}$ after heating for 20 and 40 seconds, respectively. It couldn't be isolated from samples heated for longer periods. Samples with massive E. sakazakii counts (7.68 log cfu $\mathrm{ml}^{-1}$ ) showed positive growth after 60 seconds period of heating exposure $\left(2.08 \log \mathrm{cfu} \mathrm{ml}^{-1}\right)$. Upon heating for 80 seconds the temperature achieved $96^{\circ} \mathrm{C}$ in which no survivors of E. sakazakii could be traced. These results agreed with those recorded by (Kindle et al., 1996). The effect of microwave heat treatment depends on the quantity of the product and the geometry of the vessel used. So it is logic to mention that in this experiment we used the same type of bottles and the same quantities $(100 \mathrm{ml})$ of IFM samples. It is concluded that, inasmuch as biological experiments up till now showed no evidence for the hazards of microwave heat treatment of milk (Sieber et al., 1996), it can be relay upon as a convenient and fast method to reduce microbial contamination of IFM. However, great care should be taken to ensure that milk is adequately cooled to the required temperature before it is fed to an infant.

\section{REFERENCES}

Arku, B.; Mullane, N.; Fox, E.; Fanning, S. and Jordan, K. (2008): Enterobacter sakazakii survives spray drying. International Journal of Dairy Technology, 61, 102-108. 
Biering, G.; Karlsson, S.; Clark, N.C.; Jonsdottir, K.E.; Ludvigsson, P. and Steingrimsson, O. (1989): Three cases of neonatal meningitis caused by Enterobacter sakazakii in powdered milk. J. Clin. Microbiol., 27, 2054-6.

Cawthorn, Donna-Mareè; Botha, Sharon and Corli Witthuhn, R. (2008): Evaluation of different methods for the detection and identification of Enterobacter sakazakii isolated from South African infant formula milks and the processing environment. International Journal of Food Microbiology, 127, 129-138.

Conte, F. and Passantino, A. (2008): Isolation of Enterobacter sakazakii from ass' milk in Sicily: Case report, safety and legal issues. Travel Medicine and Infectious Disease, 6, 250-252.

Farmer, J.J.; Ashbury, M.A.; Hickman, F.W. and Brenner, D.J. (1980): The Enterobacteriaceae Group: Enterobacter sakazakii: a new species of Enterobacteriaceae isolated from clinical species. Int. J. Syst. Bacteriol., 30, 569-584. Cited by Mullane, et al. (2006): Detection of Enterobacter sakazakii in Dried Infant Milk Formula by Cationic-Magnetic-Bead Capture. Applied and Environmental Microbiology, 72, 6325-6330.

FDA "Food and Drug Administration"(2002): Isolation and enumeration of Enterobacter sakazakii from dehydrated infant formula. [Online] http://www.cfsan.fda.gov/_comm/mmesakaz.html. Accessed on 20 November, 2008.

Friedemann, Miriam (2007): Enterobacter sakazakii in food and beverages (other than infant formula and milk powder). "A review" International Journal of Food Microbiology, 116, 1-10.

Gurtler, J.B. and Beuchat, L.R. (2007): Growth of Enterobacter sakazakii in reconstituted infant formula as affected by composition and temperature. Journal of Food Protection, 70, 2095-2103.

Gurtler, J.B.; Kornacki, J.L. and Beuchat, L.R. (2005): Enterobacter sakazakii: A coliform of increased concern to infant health International Journal of Food Microbiology, 104, 1-34.

Iversen, C. and Forsythe, S. (2003): Risk profile of Enterobacter sakazakii, an emergent pathogen associated with infant milk formula. Trends in Food Science \&Technology, 14, 443-454.

Iversen, C. and Forsythe, S. (2004): Isolation of Enterobacter sakazakii and other Enterobacteriaceae from powdered infant formula milk and related products. Food Microbiology, 21, 771-777. 
Kandhai, M.C.; Reij, M.W.; Gorris, L.G.; Guillaume-Gentil, O. and Van Schothorst, M. (2004): Occurrence of Enterobacter sakazakii in food production environments and households. Lancet, Jan 3; 363 (9402):39-40.

Kindle, G.; Busse, A.; Kampa, D.; Meyer-König, U. and Daschner, F.D. (1996): Killing activity of microwaves in milk. Journal of HospitalInfection, 33, 4273-278.

Lin, L.C. and Beuchat, L.R. (2007): Survival of Enterobacter sakazakii in infant cereal as affected by composition, water activity, and temperature. Food Microbiology, 24, 767-777.

Nazarowec-White, M. and Farber, J.M. (1997): Isolation, survival and growth of Enterobacter sakazakii in infant formula. J. Food Protection, 60, 226-230.

Richards, G.M.; Gurtler, J.B. and Beuchat, L.R. (2005): Survival and growth of Enterobacter sakazakii in infant rice cereal reconstituted with water, milk, liquid infant formula, or apple juice. Journal of Applied Microbiology, 99, 844-850.

Shaker; Reyad; Osaili, Tareq; Al-Omary, Wail; Jaradat, Ziad and Al-Zuby, Mahmoud (2007): Isolation of Enterobacter sakazakii and other Enterobacter sp. from food and food production environments. Food Control, 18, 1241-1245.

Sieber, R.; Eberhard, P. and Gallmann, P.U. (1996): Heat treatment of milk in domestic microwave ovens. "A review" International Dairy Journal, 6, 231-246.

Simmons, B.P.; Gelfand, M.S.; Haas, M.; Metts, L. and Ferguson, J. (1989): Enterobacter sakazakii infections in neonates associated with intrinsic contamination of a powdered infant formula. Infect. Control. Hosp. Epidemiol., 10, 398-401.

Urmenyi, A.M.C. and Franklin, A.W. (1961): Neonatal death from pigmented coliform infection. Lancet i, 313-315.

Van Acker, J.; De Smet, F.; Muyldermans, G.; Bougatef, A.; Naessens, A. and Lauwers, S. (2001): Outbreak of necrotizing enterocolitis associated with Enterobacter sakazakii in powdered milk formula. J. Clin. Microbiol., 39, 293-297.

Willis, J. and Robinson, J.E. (1988): Enterobacter sakazakii meningitis in neonates. Pediatr. Infect. Dis. J., 7, 196-199. 